\title{
THE OCCURRENCE OF OEDEMA IN INFANTILE GASTRO-ENTERITIS
}

\author{
BY \\ JOSEPH BERKELEY, M.D. D.P.H. \\ Senior Assistant County Medical Officer of Health, Westmorland
}

The occurrence of oedema during infantile gastroenteritis has been noted in the past by various writers, but few have provided detailed descriptions of the condition. Arabian writers (seventh century A.D.) record that ' in the course of the disease, the child may become bloated throughout the body or in part '; and Rush, in the eighteenth century in America, observed that 'during summer diarrhoea a swelling frequently occurs in the abdomen and limbs.' Hume (1911) appears to be the only writer who has described symptomatology and discussed etiology in some detail. In a paper entitled ' General Oedema following Gastro-enteritis in Children,' he described thirteen instances of the complications in children of ages ranging from one to four years, who developed oedema of the hands and feet three to four weeks after the onset of an attack of diarrhoea and vomiting. More recent references provide little additional information. Graham and Morris (1933), Kutumbiah (1941), and Dieckhoff and Künstler (1944), make only brief comment on the occurrence of the phenomenon, as do Thomson and Findlay in their textbook on children's diseases. In other modern paediatric textbooks, however, although descriptions are given of 'overhydration cedema' following excessive parenteral fluid administration and of 'nutritional oedema' in marasmus and the wasting diseases, the oedema of gastro-enteritis per se is not even mentioned.

\section{Present Investigation}

In view of the scarcity of information on the subject further study seemed desirable. This was begun in the infantile gastro-enteritis wards at Belvidere Hospital, Glasgow, in the summer of 1945.

The following plan of investigation was adopted:

1. All routine admissions to the wards were observed closely for the occurrence of oedema. The nursing staff, especially the morning staff who bathed the babies, were advised to be on the alert for its presence.

2. When it was noted, the patient was weighed immediately and, thereafter, daily records were started.
3. Careful notes were taken of the course of the oedema and of the concomitant clinical features.

4. Feeds of a protein hydrolysate, = ' casydrol,' were given to alternate patients (a) on admission and (b) at the onset of oedema. The purpose of this feeding experiment was to discover whether protein feeding was of value as a means of prevention or of treatment of the condition; this would be a test of the validity of the hypothesis that the oedema was due to hypoproteinaemia of nutritional origin.

\section{General Description of Cases}

A total of 176 patients were observed in the infantile gastro-enteritis wards between June 11, 1945, and Jan. 1, 1946. They presented the usual age-incidence found in the disease, 87 per cent. being under eighteen months old. Sex-incidence was the normal 3 : 2 male preponderance. Clinical features accorded with those customarily found in gastro-enteritis, inasmuch as vomiting, frequent stools, and dehydration of varying degree were present. Parenteral infections, mainly respiratory, were noted in $\mathbf{4 6}$ per cent. of cases. Although the severity and stage of illness varied from case to case, all exhibited evidence of toxaemia or dehydration or both, sufficiently grave to warrant admission to hospital.

Treatment followed the usual lines. After an initial starvation period, when only saline or 5 per cent. glucose in $\frac{\mathbf{N}}{2}$ saline feeds were administered, every alternate patient was given 'casydrol' feeds. Milk feeds, diluted as required in half-normal saline, was the alternative diet, and this was given also to those infants who could not tolerate 'casydrol.' The feeds were then built up gradually until a full dietary suitable for the patient's age could be administered. All patients received vitamin B complex tablets and vitamin C (50 mg.) tablets three times a day and daily inunction of adexolin ointment (20 per cent.). Sulphadiazine and sulphaguanidine, and, in a few cases, penicillin, were administered where indicated. When necessary gastric lavage was performed, and fluid replaced by 
'intragastric ' drip (Berkeley, 1947) or by parenteral routes.

\section{Description of Oedema Cases}

Clinical features. Among these 176 cases, no fewer than thirty-five exhibited oedema in one or more situations during their stay in hospital. The first indication of the oedema was usually on the dorsal surfaces of the feet and hands. The swelling was of rapid onset and development. It did not readily pit on pressure, but rather imparted a feeling of resilience to the examining fingers. This oedema of the feet and hands was a feature of all the cases, although not infrequently the loose tissues round the eyes were involved, and, more rarely, oedema was noted in the sacral region. In several patients the abdomen seemed distended, and some free fluid may have been present. The urine of all oedematous patients was clear; and in no case was abnormality found in the cardiovascular system. Indeed, apart from the weight changes (which are described below) no other outstanding clinical abnormalities could be detected in the oedematous patients. Most of these infants, however, showed some degree of microcytic hypochromic anaemia (Hb ranging from 40 to 70 per cent., red blood cells from 3 to $4 \cdot 5$ million and white blood cells from 6,000 to 13,000 cells per c.mm., and films showing normal cells or ring-staining microcytes). Although parenteral administration of fluid was pursued in all acutely dehydrated patients, this form of treatment was required soon after admission, and in no case did oedema develop during the administration, or within the seventy-two-hour period following. Thus the oedema which was being observed was not the well-recognized type of 'overhydration oedema' which is due to administration of excess parenteral fluid.

Three cases had received intragastric drip therapy before the onset of oedema. The fluid administered was 5 per cent. glucose in $\frac{N}{2}$ saline and daily volumes of $30 \mathrm{ml}$. per kilo of body weight had been introduced.

The general treatment of the oedematous patients differed in no way from that of the non-oedematous, but approximately half the oedematous patients were fed on 'casydrol,' the remainder continuing to receive their previous diet, which in most cases was diluted milk feeds.

Course of oedem. The course of the oedema was unexpected. Spontaneous subsidence of the oedema occurred in all cases except in four infants who died while oedema was still present. This occurred even in patients whose dietary and therapeutic regime had not been altered. The duration of visible oedema in most cases was found to range from two to eight days. Recurrence of oedema was noted in only one case. Here the initial oedema had lasted for two days; seven days later it recurred on hands and feet, and again subsided after four days. This child subsequently was discharged well.
Prognosis. Of thirty-five oedematous patients, eleven died (31 - 4 per cent.), whereas of the 141 nonoedematous patients, twenty-five died (17.7 per cent.). Although a $x^{2}$ test showed that there was no significant difference between these death rates, the clinical impression was that oedematous patients had a poorer prognosis than the non-oedematous.

In four fatal cases, oedema was still present when death occurred. The remaining seven fatal cases were oedema-free at the time of death, the time interval in these cases, between the subsidence of oedema and the onset of death, being from seven to fourteen days.

Pest-mortem examinations. Two of the fatal cases were examined post mortem. In one child no obvious lesions were found; in the other, who died while oedema was still present, histological examination of liver by Dr. Reynolds (Pathologist to the Glasgow Corporation Public Health Department) revealed extensive fatty degeneration.

Weight changes. Weight changes were a striking feature found in almost all the cases, and they provided objective confirmation of the presence and course of the visible oedema. A high increase in weight appeared with the onset of the oedema. The maximum increase occurred within twenty-four hours of onset; subsequently, the weight chart showed a downward trend corresponding with the diminution of the visible oedema. The weight increases accompanying the oedema varied from 4 to $58 \mathrm{oz}$., the average being $22 \cdot 1 \mathrm{oz}$. with standard deviation $\pm 11 \cdot 9$. The initial losses in weight which occurred simultaneously with the subsidence of the visible oedema were rapid and were accompanied by diuresis. The figures varied from 7 to $30 \mathrm{oz}$., the average being $16.8 \mathrm{oz}$, and standard deviation $\pm 7 \cdot 8$. Subsequently, during the following seven to fourteen days, most patients continued to lose weight, although in amounts not as high as the initial weight loss.

\section{Detailed Analysis of Oedema Cases}

Oedema-incidence and age of patient. Table 1 shows that oedema was confined to patients in the 0 to 16 months' age group, and that 83 per cent. of the oedema cases were one year of age and under.

Oedema-iacidence and duration of illness. Oedema was never observed during the first four days of the patient's illness. Thereafter it occurred in six cases (17-1 per cent.) during the fifth to seventh days of illness, that is, during the first week; in nineteen cases (55.7 per cent.) during the second week of ilhess; in five cases (14.3 per cent.) during and after the fourth week of illness.

Duration of visible cederna. The oedema subsided spontaneously. Four patients died while oedema was still present. In the remaining thirtyone oedematous patients, the duration of visible oedema in twenty-nine patients was from two to 
TABLE 1

OEDEMA-INCIDENCE AND AGE OF PATIENT

\begin{tabular}{|c|c|c|c|c|}
\hline $\begin{array}{l}\text { Age in } \\
\text { months }\end{array}$ & & Total cases & $\begin{array}{l}\text { Oedema } \\
\text { cases }\end{array}$ & $\begin{array}{l}\text { Percentage of } \\
\text { oedema cases }\end{array}$ \\
\hline $\begin{array}{l}0-3 \\
4-6 \\
7-9 \\
10-12 \\
13-15 \\
16-18 \\
19-21 \\
22-24 \\
25-27\end{array}$ & $\begin{array}{l}\ldots \\
\ldots \\
\cdots \\
\cdots \\
\cdots \\
\ldots \\
\ldots\end{array}$ & $\begin{array}{r}46 \\
33 \\
26 \\
16 \\
19 \\
13 \\
14 \\
1 \\
8\end{array}$ & $\begin{array}{l}8 \\
8 \\
9 \\
4 \\
5 \\
1 \\
1 \\
0 \\
0 \\
0\end{array}$ & $\begin{array}{c}17 \cdot 4 \\
24 \cdot 2 \\
34 \cdot 6 \\
25 \cdot 0 \\
26 \cdot 3 \\
7 \cdot 7 \\
0 \\
0 \\
0\end{array}$ \\
\hline Total & .. & 176 & 35 & $19 \cdot 9$ \\
\hline
\end{tabular}

eight days, and in twenty-three patients the duration was only from two to five days.

Oedema-incidence and type of feed given on admission. It had been intended to give 'casydrol ' feeds to alternate patients on admission, but some patients could not tolerate 'casydrol' and these were given diluted milk feeds instead. Thus, only one in three of the total patients received protein feedings on admission. Table 2 shows that, despite ' casydrol' feeding, ten infants developed oedema. Also, the incidence of oedema in casydrol-fed patients was little different from the incidence in milk-fed infants. It can be concluded that 'casydrol' feeding was ineffective in preventing oedema.

Casydrol and treatment. After the onset of oedema, alternate patients had been given 'casydrol' feeds, so analysis of the oedematous patients' dietary showed the following four groups of patient:

Group 1 consisted of eighteen patients who had been given milk feeds before onset and milk feeds after onset of oedema.

GroUP 2 consisted of eight patients given milk before and 'casydrol' after onset of oedema.

GrOUP 3 consisted of six patients given 'casydrol ' before and 'casydrol' after onset of oedema.

Group 4 consisted of one patient given ' casydrol ' before and milk after onset of oedema.

The average duration of oedema was: group 1,

\section{TABLE 2} OEDEMA-INCIDENCE AND TYPE OF FEED
GIVEN ON ADMISSION*

\begin{tabular}{ccc|cc}
\hline $\begin{array}{c}\text { Type of feed } \\
\text { given on } \\
\text { admission }\end{array}$ & $\begin{array}{c}\text { Total no. of } \\
\text { cases }\end{array}$ & $\begin{array}{c}\text { Cases who developed } \\
\text { oedema }\end{array}$ \\
\hline $\begin{array}{c}\text { Diluted milk } \\
\text { 'Casydrol ' }\end{array}$ & $\ldots$ & 113 & No. & $\%$ \\
\hline
\end{tabular}

- Two patients who developed oedema within forty-eight hours after admission are not included in this table.
$5 \cdot 11$ days; group $2,4 \cdot 82$ days; group $3,4 \cdot 67$ days.

The duration of oedema in the patient in group 4 was 4 days. Groups 1, 2, and 3 showed no significant difference between their mean duration of oedema.

Duration of oedema and sulphonamide treatment. Of the thirty-one oedematous patients, eight had received no drug treatment (group A), twelve had received sulphaguanidine (group B), and eleven had received sulphadiazine (group $C$ ). The mean duration of oedema in group $A$ was 5.0 days, in group B $4 \cdot 2$ days, and in group $C 4 \cdot 8$ days. Statistical analysis showed no significant difference between these means. Thus, sulphonamide therapy did not influence the duration of oedema.

Four patients who died while oedema was still present, are not included in this analysis.

\section{Discussion}

The paucity of literature on an apparently not uncommon condition is puzzling, but it should be noted that this complication of infantile gastroenteritis is typically unobtrusive. The oedema appears rapidly and subsides spontaneously and swiftly: it occurs usually after the acute stage has subsided and is not accompanied by obvious change in the clinical picture. It seems possible that observers not specially on the look-out for the condition may have missed its occurrence or regarded it as being less frequent than it actually is.

Weight changes. The weight changes, which were positive confirmation of the visible oedema, varied greatly among the individual patients. The range of weight increases found here accord with the range of spurious weight gains found in nephritis, serum disease, and oedema of premature infants (Holt) and in overhydration oedema following excessive parenteral fluid therapy (Brown et al, 1943).

Etiology. The etiology is obscure and has not been solved by the present investigation. However, some findings of negative value have emerged, and it may be worth while reviewing these and then discussing the possible causes which remain.

Nutritional hypoproteinaemia. Although this hypothesis is favoured by Graham and Morris (1933), the findings in the 'casydrol' experiments do not support this view. The 'casydrol ' feeding provided an adequate protein intake, but did not prevent the occurrence of oedema and was ineffective in shortening the oedema's duration. While it might be argued that the 'casydrol' was not absorbed by the severely ill patients on account of rapid peristalsis or derangement in gastro-intestinal function, this argument is refuted by the experiments by Shohl (1943) who found that despite the presence of vomiting, diarrhoea, and acidosis, nitrogen was absorbed and retained when given orally in the form 
of casein hydrolysate. Also, in the present series, oedema usually occurred when normal gastrointestinal function and presumably normal absorption were present.

Therefore, it seems unlikely that nutritional hypoproteinaemia is a major factor in etiology.

Vitamin B deficiency. Likewise, vitamin B deficiency does not appear to be a major etiological factor. There is no proof that the vitamin B preparation which had been administered as a routine to all patients during their stay in hospital had been absorbed. On the other hand, had vitamin B deficiency occurred to an extent sufficient to cause oedema, other signs of the deficiency would have been present, and these (described by Fehily, 1947) were never observed in the oedematous infants.

Possible causes. Albuminuria, heart disease, and macrocytic anaemia (described by Holmes, 1945), are other possible causes of oedema, but were never found in the patients in the present series.

'Overhydration oedema' due to administration of excessive amounts of parenteral fluid has already been excluded as a cause of the condition.

Hume (1911) suggested that the oedema was related to a deficiency in secretion of the suprarenal glands, for he found fibrosis in these glands in two cases at necropsy. He also reported that oedematous children, treated by injections of adrenaline hydrochloride, appeared to show improvement. However, in view of the characteristic tendency of the oedema to spontaneous cure-as observed in the present series-the therapeutic efficacy ascribed to adrenaline injections is open to doubt.

The remaining possibilities. When the above have been excluded from the list of possible causes, the range of hypotheses is narrowed, and attention can be focused on the possibilities which remain. These are: (a) impairment in function of capillary endothelium, (b) impairment in liver function, and (c) impairment in renal function.

\section{Impairment in Function of Capillary Endo- THELIUM}

Damage to the capillary endothelium is well recognized as a cause of oedema. Dieckhoff and Künstler (1943) favour this hypothesis to account for the oedema of gastro-enteritis, and Sheldon (1943) stated that 'oedema which occurs in marasmic and severely-wasted infants is attributable to changes in permeability of the capillaries resulting from their poor nutrition.' The oedema of acute nephritis appears also to be due to this cause, since the oedema-exudate has a high protein content (usually over 1 per cent.) and changes in the peripheral vessels can often be found (Cumulative Supplement, British Encyclopaedia of Medical Practice, 1947).

Unfortunately there is no scientific evidence to confirm that capillary damage is a cause of oedema in infantile gastro-enteritis. Also some features of the condition are not readily explained by the hypothesis. Thus, if the oedema were due only to the effect of toxaemia on the capillaries, it should surely have become manifest at the early stage of the illness when toxaemic effects were maximum, rather than during the second and third weeks when the oedema usually occurred. Also, if the spontaneous subsidence of oedema is to be accounted for by the rapid recovery of capillary function, the reason for this rapid recovery is not quite clear.

It must be concluded that although impairment of capillary function is a possible cause of oedema, it does not alone account for all the observed features of the condition.

IMPAIRMENT IN LIVER FUNCTION. Impairment in liver function is another possible cause of the oedema. In infantile gastro-enteritis, liver damage is a common-in fact, the only common-finding at autopsy; and Thompson (1936) and Lawrence (1946) have brought evidence to show that the occurrence of liver damage may impair the manufacture of serum protein and result in hypoproteinaemia and oedema. On this basis, the spontaneous subsidence of the oedema would be due to the occurrence of compensatory regenerative changes in the liver.

However, there is at present no available data on the fluctuations of the serum protein levels in infants before, during, and after the occurrence of oedema. Until this information is obtained, the hypothesis of liver damage remains a possible but purely theoretical cause.

IMPAIRMENT IN RENAL FUNCTION. The important experiments by McCance and Young (1941) on the kidney function of infants have demonstrated clearly the relative inefficiency of these organs during the first year of life. These workers showed that, at low urine flows, the concentration of solids in the infants' urine does not increase as it would do in adults, and that, if oliguria occurs as a result of dehydration, some degree of salt and water retention inevitably occurs. Simmons (1944) has summarized the situation in these words: '. . . the infants' urine is always a dilute urine. Therefore, any infant short of water is likely to have renal failure with retention of salt and urea, and with oedema due to salt-bound water.' It is thus apparent that infants with gastro-enteritis who suffer from oliguria are liable to develop oedema due to salt retention.

The theory of salt-retention as a cause of the oedema possesses several points in its favour which may be worth enumerating. These are:

1. Oedema incidence was restricted to the young age-groups in whom renal function is least efficient.

2. Since cows' milk contains more protein and salt than breast milk, artificially-fed infants have a greater load on their excretory apparatus than breast-fed infants 
and thus have a greater tendency to develop renal failure.

3. The subsidence of the oedema (which is a puzzling feature of the condition) may have been due to the patient's return to a normal fluid balance when the cessation of diarrhoea and vomiting allowed the excretion of salt and the release from the tissues of salt-bound water.

It seems likely that impaired renal function is an important factor in the etiology.

\section{Summary and Conchuions}

In a series of 176 cases of infantile gastro-enteritis, oedema occurred as a complication in thirty-five (19.6 per cent.).

The preponderant incidence was in the age group under one year, although oedema was noted in patients up to sixteen months.

Spontaneous subsidence of the oedema occurred between two and eight days after onset. In this series oedema never occurred before the fifth day of illness but appeared thereafter, in more than half the cases during the second week of illness, and in almost a third during the third and fourth weeks of illness.

Apart from weight changes which fluctuated parallel with the waxing and waning of the oedema, and from the presence in a few cases of microcytic hypochromic anaemia, there was no other clinical abnormality detected.

The occurrence and duration did not seem to be influenced by the diet. Thus, 'casydrol ' feeds had no effect on frequency and duration of the oedema, and vitamin $B$ deficiency did not appear to be related to the condition.

Comparison of patients treated by sulphonamides with those untreated, indicated that neither sulphaguanidine nor sulphadiazine were related to the production or duration of the oedema.

The death rate in the oedematous patients was 31.4 per cent. (eleven out of thirty-five), and in the non-oedematous, $17 \cdot 7$ per cent. (twenty-five out of 141).
Although a chi-squared test showed that the difference between these death rates was not significant, the chi-squared values were sufficiently close to indicate a tendency for mortality to be higher in oedematous cases than in non-oedematous.

The etiology is obscure, and the present investigation, while enabling the exclusion of some of the possible causes, has not solved this problem. Probably several factors are implicated; of these, the likeliest appear to be: (a) impairment in capillary function; (b) impairment in liver function; (c) impairment in kidney function.

Thanks are due to Dr. T. Archibald, PhysicianSuperintendent, Belvidere Hospital, Glasgow, for his full co-operation and encouragement, and to the nursing staff; also to Dr. R. A. Robb, Statistics Department, Glasgow University, for advice on statistical methods.

\section{REFERENCES}

Arabians (7th Century) in Ruhräh, J., Pediatrics of the Past (1925). New York. p. 25

Berkeley, J. (1947). Glasgow med. J., 28, 224.

Brown, H. R., Clark, W. F., Jones, N., Walther, J., and Warren, S: L. (1943). J. clin. Invest., $22,471$.

British Encyclopaedia of Medical Practice. Cumulative Supplement (1947). London. p. 192.

Dieckhoff, J., and Künstler, S. (1944). Bull. Hyg. Lond., $19,176$.

Fehily, L. (1947). Brit. med. J., 1, 220.

Graham, S., and Morris, N. (1933). Acidosis and Alkalosis. Edinburgh. p. 175.

Holmes, E. G. (1945). Brit. med. J., 2, 561.

Hume, W. E. (1911). Ibid., 2, 478.

Holt, L. E., and McIntosh, R. (1940). Diseases in Infancy and Childhood. London. Eleventh edit., pp. 325, 827.

Kutumbiah, P. (1941). Antiseptic, 38, 471.

Lawrence, J. S. (1946). Lancet, 1, 41.

McCance, R. A., and Young, W. F. (1941). J. Physiol., 99, 265

Rush, B. (18th Century) in Ruhräh, J., Pediatrics of the Past (1925). New York. p. 426.

Sheldon, W. (1943). Diseases of Infancy and Childhood. London. 103.

Shohl, A. T. (1943). J. clin. Invest., 22, 257.

Simmons, J. H. (1944). Publ. Hlth., Lond., 57, 44.

Thompson, W. H., et al. (1936). J. Pediat., 9, 604.

Young, W. F. (1943). Proc. roy. Soc. Med., 36, 219. 